\title{
MODELLING OF BUBBLY AND ANNULAR TWO-PHASE FLOW IN SUBCEANNEL GEOMETRIES WITH BACCHUS-3D/TP
}

\author{
by \\ M. Bottoni* and R. W. Lyczkowski** \\ -Materials and Components Technology Division \\ *"Energy Systems Division \\ Argonne National Laboratory \\ 9700 South Cass Avenue \\ Argonne, Illinois 60439 \\ FAX: $708-252-3250$ \\ fin 21994 \\ $0 \mathrm{~S} \times 1$
}

January 1992

\begin{abstract}
The submitted manuscript has been authored by a contractor of the U.S. Government under contract No. W-31-109-ENG-

38. Accordingly, the U.S. Government retalns a nonexclusive, royalty-free license to publish or reproduce the published form of this contribution. or allow others to do so. for U.S. Government purposes.
\end{abstract}

Manuscript to be submitted to Nuclear Engineering and Design

"Work sponsored by Laboratory-Directed Research and Development Funds, Argonne National Laboratory.

\section{DISCLAIMER}

This report was prepared as an account of work sponsored by an agency of the United States Government. Neither the United States Government nor any agency thereof, nor any of their employees, makes any warranty, express or implied, or assumes any legal habilitys, product, or bility for the accuracy, completeness, or usefulness of any information, owned rights. Referprocess disclosed, or represents that its use would not infringe priva trade name, trademark, ence herein to any specific commercial product, process, or service by tendorsement, recommanufacturer, or otherwise does not necessarily constitute or imply its ency thereof. The views mendation, or favoring by the United States Government or not necessarily state or reflect those of the

and opinions of authors expressed herein do not

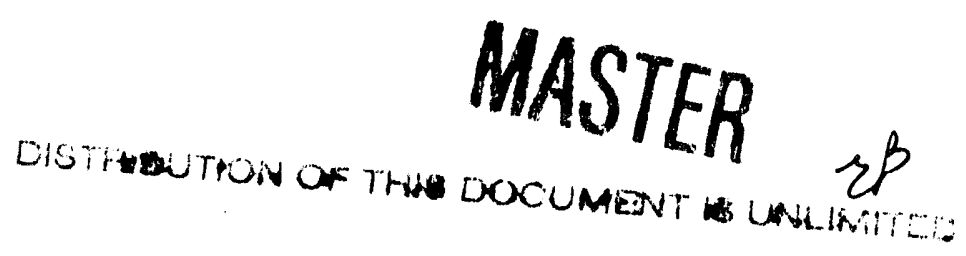


The theoretical and computational bases of the BACCHUS-3D/TP computer program are reviewed. The computer program is used for thermal-hydraulic analyses of nuclear fuel bundles under normal and accident conditions. The present program combines two models and solution procedures previously used separately. namely, the Improved Slip Model (ISM) and the Separated-Phases Model (SPM). The former model uses mixture equations with accounting for slip between the phases, whereas the latter uses separate continuity and momentum equations. At the present stage of development, both assume thermodynamic equilibrium.

Techniques used to affect smooth transition between the two models are described, including treatment of frictional pressure drop and solution of the Poisson and momentum equations. A detailed derivation of the computation of mass transfer between the phases is given because it is a central and novel feature of the model. 


\section{Introduction}

In the framework of safety analysis of Liquid Metal Fast Breeder Reactors (LMFBRs), the Fast Breeder Reactor Project at the Kernforschungszentrum Karlsruhe (KfK) has sponsored the development of a computer program that describes multidimensional thermal-hydraulic behaviour of fuel rod bundles under nominal and accident conditions. The code BACCHUS-3D/SP (Single Phase) has been developed. It describes coolant behaviour of single-phase flow, up to inception of boiling, in a two- or three-dimensional approximation of bundle geometry, which is the hexagonal rod array typical of LMFBRs. This version of the program was documented from the theoretical viewpoint in 1983 in [1], and its experimental verification was published in 1985 [2].

Unlike other well-known programs, e.g., the SABRE [3], ASFRE [4], and SABENA [5] codes, which describe the thermal-hydraulic behaviour of LMFBR rod clusters with the so-called "subchannel analysis" concept (triangular control cells), the BACCHUS program relies on the concept of volume porosities, surface permeabilities, distributed resistances, and heat sources, typical of the "porous-body"model approach. The basic idea consists of grouping several subchannels to form a larger computational cell within which the actual geometrical configuration is distributed.

The single-phase-flow version of the BACCHUS code provided the basis and the initialization conditions for the development of the two-phase-flow version of the code. At an intermediate stage of evolution, documented in Ref. [6], there existed two separate variants in which two-phase flow was described by a Slip Model (SM) and a Separated-Phases Model (SPM).

Numerical results obtained with the SM show its limits of application when the vapour volume fraction, $\alpha$, approaches 1.0 over wide regions of the simulated test section. Under these conditions, the calculation of pressure drops with the Lockhart-Martinelli two-phase multipliers becomes questionable. Theoretically, for void fractions larger than $\approx 0.6$, the liquid and vapour phases deserve separate treatment on the basis of two coupled systems of governing equations. 
Even within its domain of application, the SM is characterized by inherent deficiencies: (1) the slip ratio is not constant during evolution of two-phase flow and generally rises with increasing void fraction; (2) it is difficult to correctly define the physical properties of the coolant mixture and to compute the time derivative of the mixture density $\partial \rho_{\mathrm{m}} / \partial t$ near vold fractions approaching 1.0. The use of thermodynamic quality as a weighting factor for defining the physical properties of the mixture allows for a smooth transition between single-and two-phase-flow calculations at inception of boiling, but becomes questionable beyond some threshold value of the void fraction. When the phases are treated separately, this problem does not exist.

To cope with these difficulties, we first allowed for a variable slip ratio by coupling it to the vold fraction. The resulting SM is referred to hereafter as the Improved Slip Model (ISM). Then, we coupled the separate code versions into an integrated program, allowing a smooth transition between the SM and the model of separated phases within the framework of a numerical algorithm that simultaneously solves both systems of conservation equations.

The goal of this paper is to describe in detail the techniques and experiences related to linking the Slip and Separated Phase models and the resolutions that we adopted.

In Section 2, we briefly describe the geometrical model used to represent the pin bundle typical of LMFBRs and give the fundamental equations used for both ISM and SPM. In Section 3, we describe the solutions adopted for assuring continuity of mass flow and pressure distribution in the transition between the models. Section 4 describes the rigorous computation of the mass of coolant vaporizing or condensing and thereby, the enthalpy and momentum exchange between the phases, with a new approach based on the entropy equation.

\section{Geometrical Model and Conservation Equation}

\subsection{Geometrical Model}

The BACCHUS computer programme has been structured to describe hexagonal arrangements of rods in bundles typical of LMFBRs. A complete reactor bundle, or a 
sector bounded by either ideal geometrical or material surfaces, can be described. Inlet and outlet bundle sections can be simulated. Additional options are provided for simulating unheated pins, pins with different diameters, displacements of pin axes, and grid spacers.

The local conservation equations describing the coolant flow are integrated over appropriate control volumes. Staggered meshes are used to define dependent variables (mass flows, pressure, and enthalpy) and, correspondingly, different cells are used to accomplish the macroscopic balances. The main control volumes ("centered cells") used for the mass and enthalpy balances are bounded in the axial direction by two planes perpendicular to the bundle z-axis that are a distance $\Delta z$ apart; in the radial direction, by planes through the pin axes $\Delta \mathrm{r}$ apart; and in the azimuthal direction, by two planes passing through the bundle axis. The azimuthal direction is referred to as the s-coordinate. The control volumes used for the balance of the scalar components of the momentum equations ("displaced cells") are formed by adjacent halves of two neighbouring main control volumes. Scalar quantities (pressure, enthalpy, temperature, etc.) are defined in the mid-point of a centered control cell, whereas the scalar components of vector quantities (mass flows, velocities, etc.) are defined in the mid-points of the respective boundaries of the centered cell (which coincide with the mid-points of the displaced cells when equidistant spacing is used).

For the main control volumes, the axial index is $\mathrm{JC}=2, \ldots, \mathrm{MC}$; the radial index is $\mathrm{IC}=1, \ldots, \mathrm{NC}$; and the azimuthal index is $\mathrm{IT}=1, \ldots, \mathrm{NTH}$. Indexing conventions used for the radial and azimuthal directions are shown in Fig. 1 for one-half of a 37pin bundle divided into 12 azimuthal sections. Up to 48 azimuthal sectors can be taken into account. In the following description, the node (IC, JC, IT) is indexed as $(i, j, k)$. Cell faces and velocity components are indexed $i \pm 1 / 2, j \pm 1 / 2, k \pm 1 / 2$, in the usual convention.

We impose pressure boundary conditions at the outlet of the bundle and either pressure or velocity boundary conditions at the inlet. Velocity boundary conditions at ideal geometrical surfaces or at material surfaces can be assumed with or without. slip. 
All cells are characterized by a total volume $\mathrm{V}$, a volume occupied by the fluid $\mathrm{V}_{\mathrm{f}}$. an area $A_{w}$ of the solid (wall)-flutd interfaces, by areas of lateral faces $S_{\alpha}$ (the subscript $\alpha$ refers to the general coordinate direction), and cross flow areas $S_{f} \alpha$. For every cell, we define the surface permeabllities or area obstruction factors $\gamma_{\alpha}=$ $S_{f \alpha} / S_{\alpha}$ as the ratio of the respective flow area to the total area. The volume porosity $\varepsilon$ $=V_{f} / \mathrm{V}$ of a cell is defined as the ratio of the volume occupied by the fluid to the total cell volume. In an undisturbed geometry, the volume porosity is equal to the surface permeability in the axial direction.

An equivalent fuel pin, with geometrical data corresponding to those of real pins, is associated with every main control volume. For every equivalent pin, we consider the heating element (fuel or electrical heater) and a cladding, separated from the fuel by a gap of given width. In the axial direction, gas plena, fission, and blanket zones can be represented with different material properties.

\subsection{Conservation Equations}

The governing equations for the conservation of mass, momentum, and energy of the coolant for the ISM and SPM, are given in this section.

If we denote the general dependent variable as $\phi$, the corresponding conservation equation has the following form for the ISM and SPM (see Nomenclature)

$$
\begin{aligned}
& \frac{\partial}{\partial t}(\rho \phi)+\frac{\partial}{\partial x_{1}}\left(\rho u_{1} \phi\right)=\frac{\partial}{\partial x_{1}}\left(\Gamma_{\phi} \frac{\partial \phi}{\partial x_{1}}\right)+S_{\phi \cdot} \\
& \text { (Unsteady)(Convection) (Diffusion) (Source) }
\end{aligned}
$$

which can also be written as

$$
\partial(\rho \phi) / \partial t+\partial\left(J_{\phi 1}\right) / \partial x_{1}
$$

with the definition of the total (convective plus diffusive) flux

$$
\mathrm{J}_{\phi 1}=\rho \mathrm{u}_{i} \phi-\Gamma_{\phi} \partial \phi / \partial \mathrm{x}_{1}
$$


The diffusion coefficient $\Gamma_{\phi}$ and the source term $S_{\phi}$ are specific to each meaning of $\phi$. These terms are given in Table I for all conservation equations, together with appropriate densities $\rho$ and velocities $u_{1}$.

The single-phase-flow calculation is governed by a system of equations derived from the mixture equations, replacing the mixture density, velocity, and enthalpy $\left(\rho_{m}, u_{m}, h_{m}\right)$ by the symbols for the liquid phase $\left(\rho_{1}, u_{11}, h_{1}\right)$, and suppressing the terms containing the slip velocity $\left(\mathrm{V}_{\text {sli }}=0\right)$.

In the case where $V_{\mathrm{g} 1}=\mathrm{V}_{\mathrm{ll}}$, one obtains, as a subcase, the Homogeneous Equilibrium Mixture (HEM) Model.

Let us consider a control volume centered around node (i, j, k). Integration of eq. (2) over this control volume and application of the divergence theorem yields

$$
\begin{aligned}
& \int_{V_{f}} \partial(\rho \phi) / \partial t d V+\int_{A_{f, 1+1 / 2}} J_{\phi 1} d A-\int_{A_{f, 1-1 / 2}} J_{\phi 1} d A+\int_{A_{f, j+1 / 2}} J_{\phi j} d A \\
& -\int_{A_{f, j-1 / 2}} J_{\phi j} d A+\int J_{A_{f, k+1 / 2}} d A+\int_{A_{f, k-1 / 2}} J_{\phi k} d A=\int S_{V_{f}} d V
\end{aligned}
$$

Next, the time-dependent terms are discretized. Using the definitions of the mean values of the fluxes $J_{\phi}$ 's over the bounding surfaces and of mean values over the fluid volume $V_{f}$, we transform eq. (4) into an algebraic equation for the seven unknowns $\phi_{\beta}$ $(\beta=0,1, \ldots 6)$ at time level $t_{n+1}$ :

$$
a_{o} \phi_{o}^{n+1}+\sum_{\beta=1}^{6} a_{\beta} \phi_{\beta}^{n+1}=b_{o}^{n} .
$$

Subscript $O$ in eq. (5) refers to the centre node $(\mathfrak{i}, \mathrm{j}, \mathrm{k}$ ) considered, whereas indices $(1,2),(3,4),(5,6)$ refer to the neighbouring nodes in the three coordinate directions, respectively. The right-hand side of eq. (5) collects all terms at time level $t_{n}$. Equation (5) is formally identical with the equation that would be obtained by discretizing Poisson's equation.

In practice, the momentum equations are actually combined with the continuity equations of the respective phases. The densities at the new time level are then 
linearized to form an algebratc equation for pressure. This process, the so-called "pressure solution method" is equivalent, from an analytical vlewpoint, to taking the divergence of the momentum equation written in vector form. The analytical development involved is complex and will not be repeated here because it can be found in Ref. [7].

The standard numerical solution of the discretized Poisson equation, eq. (5), is based on the L.U (lower, upper) decomposition technique developed by Doolittle [8], a variant of the Cholesky method, which yields the exact solution. In the case of the energy equation, and for single-phase-flow calculations only, a Runge-Kutta method of order 4 is also avallable. The limits for application of the matrix decomposition method are given by the requirement of storing the full band of the matrix of the coefficients of the Poisson equation. The computing time increases strongly with increasing problem size. Therefore, an alternative computational method to the large-storage-demanding matrix decomposition technique has been provided.

This alternative consists of an advanced variant of the Alternating Direction Implicit $(A D I)$ method, which we adapted to the two-phase-flow simulation. This scheme requires almost no additional core storage and, unlike older schemes, can be vectorized to a high degree. Thus, it is faster by a factor of ten with respect to classical variants. For problems with more than $\approx 5000$ meshes, it becomes faster than the Cholesky matrix decomposition technique. Both solution methods yield the same numerical results. Details of the ADI variant used for two-phase flow are given in Ref. [9].

\section{The Integrated-Code Version}

The current version of the BACCHUS code combines the ISM and the SPM into an integrated program that allows for a description of boiling with a smooth transition from one model to the other. 'This holds for both the evaporation and condensation processes. In this section, we explain the techniques used to couple the two models, experiences encountered, and potential limitations. We give an overview of the ISM and SPM, emphasizing the topics that must be considered in the linking process. We also discuss the problems that were solved to allow a smooth transition from one model to the other and give an overview of the integrated models. 


\subsection{Overview of the Improved Slip Model and the Separated-Phases Model}

The slip model can be used by specifying either a fixed slip ratio given by

$$
\mathrm{H}_{\mathrm{l}}=\frac{\mathrm{u}_{\mathrm{g}}}{\mathrm{u}_{\mathrm{l} 1}} \quad(\mathrm{i}=\mathrm{r}, \mathrm{s}, \mathrm{z})
$$

for the three coordinate directions, radial, azimuthal, and axial, or a normalized slip velocity given by

$$
U_{S \ell 1}^{N}=\frac{u_{g l}-u_{\ell l}}{u_{m l}} \quad(i=r, s, z) .
$$

In the second option, the slip ratio is not constant but varies according to

$$
\mathrm{H}_{1}=\frac{\mathrm{u}_{\mathrm{gl}}}{\mathrm{u}_{\ell \mathrm{l}}}=1+\mathrm{U}_{\mathrm{S} \ell \mathrm{N}}^{\mathrm{N}} \frac{\mathrm{u}_{\mathrm{ml}}}{\mathrm{u}_{\ell 1}} \quad(i=\mathrm{r}, \mathrm{s}, \mathrm{z})
$$

These two options extend the classical slip models found in the literature [10]. They are applicable to small or moderate void fractions $(0 \leq \alpha \leq \sim 0.6)$, i.e., as long as the coolant can be represented as a mixture. When utilized above $\alpha \simeq 0.6$, experience shows that the computed vapour velocities are too small compared to the liquid and mixture velocities; thus, the pressure drops are underestimated and the evolution of the two-phase flow-region is not correctly reproduced.

The normalized slip velocity is given as a function of the void fraction

$$
U_{S \ell 1}^{N}=f(\alpha), \quad(i=r, s, z)
$$

where, usually, $f(\alpha)=18 \alpha$. We also model the two-phase pressure drop multiplier as a function of $\alpha$ by

$$
\phi_{1}^{2}=1+K_{1}=1+c l u_{m l} \mid U_{S \ell l}^{N}(\alpha) \quad(1=r, s, z)
$$

with $c=1+1 \cdot 5$

Because the slip ratio is now dependent on the void fraction, more realistic vapour velocities, hence pressure drops, are computed. The applicability range of the ISM thus extends to relatively large void fractions $(\alpha \simeq 0.9-0.95)$, although the 
physical representation of the coolant as a mixture is no longer correct. The limits of applicability of the ISM are reached when relatively large regions of a bundle are at, or close to, dry-out conditions.

The main physical assumption on which the SPM is based is that the phases flow separately, but in thermodynamic equilibrium so that only one temperature, corresponding to the saturation pressure, needs to be computed. Furthermore, the assumption of equal pressure in both phases within a computational cell is retained for the SPM. The liquid phase is assumed to wet the surfaces of pins or hexagonal canning, whereas the vapour is assumed not to come in contact with them before dry-out.

Because of these modeling assumptions, the SPM is not reasonably applicable to void fractions below a given threshold, which can be assumed as $\alpha_{\min }=0.5$ to 0.6. For this reason, the code version based on the SPM, though originally developed to stand alone, has now been integrated with the ISM.

\subsection{Coupling the ISM and SPM}

The main experiences encountered in linking the ISM and SPM code versions are summarized in this section.

\subsubsection{Solution of Poisson Equation for Pressure}

The SPM is based on the assumption that the pressure in the two phases within a computational cell is equal. It would be possible to compute the pressure distribution within the SPM with either of the two Poisson equations (for the liquid or for the vapour phase). For small and moderate void fractions, the Poisson equation for the liquid phase is more suitable, for large void fractions the vapour-phase equation performs better. The problem arises when switching from the ISM (small $\alpha)$ to the Poisson equation for the liquid phase only (moderate $\alpha$ ), to the one for the vapour phase (large $\alpha$ ). If we sum the two Poisson equations of the SPM model, the problem is simplified for two reasons: 1) there is only one switch needed between ISM and SPM; 2) the compressibility term $\partial \rho_{m} / \partial t$ can be treated in the combined 
Poisson equation in exactly the same way as it is treated in the ISM. This contributes to a smooth transition between the two models.

\subsubsection{Computation of Velocity Components}

In the ISM, the mass flow components, hence the velocity components of the mixture, are first computed from the mixture momentum equation. Then, the velocity components of both phases are given as a function of the normalized slip velocities given by eq (9).

In the SPM, the situation is reversed: the velocity components of the phases are first computed from the momentum equations and then the velocity components of the mixture are obtained directly by means of their definitions. These values are needed for the solution of the enthalpy equation in terms of mixture quantities.

In the transition between ISM and SPM, the velocity components must not undergo discontinuity. A smooth transition would not be possible in the usual SM. but has been attained in the ISM by proper choice of normalized slip velocities as a function of the void fraction. Smooth transition of the velocity components also ensures a continuity in the pressure-drop computation, as discussed in Sec. 3.2.4.

\subsubsection{Momentum Exchange Between Phases}

The momentum exchange between phases is due to wall friction, interface (liquid-vapour) friction, and mass exchange due to vaporization or condensation.

To illustrate these problems, we refer to the axial component of the momentum equations for both phases from eqs I.6 and I.7 in Table I, given by

$$
\frac{\partial}{\partial t}\left(\rho_{\ell}^{\prime} w_{\ell}\right)+\frac{\partial}{\partial x_{1}}\left[\left(\rho_{\ell}^{\prime} u_{\ell 1}\right) w_{\ell}-\mu_{\ell} \frac{\partial w_{\ell}}{\partial x_{1}}\right]=-(1-a) \frac{\partial p}{\partial z}-\rho_{\ell}^{\prime} g_{z}-R_{\ell z}-
$$

$$
-K\left(w_{l}-w_{g}\right)-\left([0, M] w_{l}-[0, M] w_{g}\right)
$$

(c) 


$$
\frac{\partial}{\partial t}\left(\rho_{g}^{\prime} w_{g}\right)+\frac{\partial}{\partial x_{1}}\left[\left(\rho_{\ell}^{\prime} u_{g l}\right) w_{g}-\mu_{\ell} \frac{\partial w_{g}}{\partial x_{1}}\right]=-a \frac{\partial p}{\partial z}-\rho_{g}^{\prime} g_{z}-R_{g z}+
$$

$$
+K\left(w_{\ell}-w_{g}\right)-\left([0, M] w_{l}-[0,-M] w_{g}\right) \quad(i=r, s, z) .
$$

(b)

(c)

Summing the coefficients of the Poisson equations of both phases is equivalent to summing the momentum equations, which yields

$$
\begin{aligned}
& \frac{\partial}{\partial t}\left(\rho_{m} w_{m}\right)+\frac{\partial}{\partial x_{1}}\left[\left(\rho_{\ell}^{\prime} u_{\ell l}\right) w_{\ell}+\left(\mu_{g} u_{g 1}\right) w_{g}-\mu_{\ell} \frac{\partial w_{\ell}}{\partial x_{1}}-\mu_{g} \frac{\partial w_{g}}{\partial x_{1}}\right]= \\
= & -\frac{\partial p}{\partial z}-\rho_{m} g_{z}-R_{\ell z}-R_{g z} \quad(1=r, s, z) .
\end{aligned}
$$

In the summing process, terms (a), representing wall friction, are conserved, but terms (b) and (c) cancel each other. These two latter terms represent the momentum exchanges due to the interphase friction and mass exchange. respectively. It is clear that these physical processes cannot be neglected; therefore, the problem consists in devising a modeiling approach that takes them into account, while retaining the assumption of equal pressure in both phases, which allows for solving only one Poisson equation. These problems have been solved as follows:

Terms (a).

If $\alpha=1, R_{l_{z}}=0$, and $R_{g z} \neq 0$. Let $\alpha_{\min }$ be the lower threshold of applicability of the SPM. If $\alpha_{\min } \leq \alpha<1$, we model a liquid film wetting cell surfaces while it is assumed that the vapour does not come into contact with these surfaces.

Therefore, $R_{\ell z} \neq 0$, while $R_{g z}=0$. Thus, formally, we can use the term $R_{g z}$. which is not cancelled in equation (12) to model the momentum exchange due to interface friction.

Terms (b).

By letting

$-R_{g z}=K\left(w_{\ell}-w_{g}\right)$, 
we model the interface friction for the vapour phase only.

Terms (c).

We model the momentum exchange due to mass transfer by assigning it only to the phase that acquires it (and neglecting the momentum lost by the other phase). For both $M>0$ and $M<0$, we may assume [11] that

$G_{\ell}=\left[0,\left\{-[0, M] w_{l}+[0,-M] w_{B}\right\}\right] \begin{cases}=0 & \text { by evaporation } \\ =|M| w_{B} & \text { by condensation, }\end{cases}$

and

$$
G_{g}=\left[0,\left\{[0, M] w_{l}-[0,-M] w_{g}\right\}\right] \begin{cases}=M w_{l} & \text { by evaporation } \\ =0 & \text { by condensation. }\end{cases}
$$

Calculation of the evaporation or condensation rate $M$ is made taking into account both enthalpy transfer and pressure variations, as explained in Sec. 4.

Summing Eqs. (11) and (12) and taking into account Eqs. (14) and (15) results in

$$
\begin{aligned}
& \frac{\partial}{\partial t}\left(\rho_{m} w_{m}\right)+\frac{\partial}{\partial x_{1}}\left[\left(\rho_{\ell}^{\prime} u_{\ell 1}\right) w_{\ell}+\left(\rho_{g}^{\prime} u_{g 1}\right) w_{g}-\mu_{\ell} \frac{\partial w_{l}}{\partial x_{1}}-\mu_{g} \frac{\partial w_{g}}{\partial x_{i}}\right]= \\
= & -\frac{\partial p}{\partial z}-\rho_{m} g_{z}-\left(\frac{d p}{d z}\right)_{2 \phi}+G_{\ell}+G_{g} \quad(i=r, s, z),
\end{aligned}
$$

with the definition

$$
\begin{aligned}
\left(\frac{d p}{d z}\right)_{2 \phi} & =\left(\frac{d p}{d z}\right)_{l}+\left(\frac{d p}{d z}\right)_{1}=R_{\ell z}+R_{g z}= \\
& =R_{\ell z}-K\left(w_{l}-w_{g}\right) \quad(i=\text { interface }) .
\end{aligned}
$$

\subsubsection{Calculation of Two-Phase Pressure Drops}

Smooth transition between ISM and SPM also requires continuity in the calculation of two-phase pressure drops. In the transition region, continuity is ensured by letting 


$$
\left(\frac{d p}{d z}\right)_{2 \phi}=\phi_{I S M}^{2}\left(\frac{d p}{d z}\right)_{m}=R_{l z}+R_{g z}=\left(\frac{d p}{d z}\right)_{l}+\left(\frac{d p}{d z}\right)_{g} \phi_{S P M}^{2} .
$$

which allows for a refined calculation of $\phi_{\text {SPM }}^{2}$, replacing the value given by eq. (10).

\subsection{Overview of the Integrated Code Version}

Traditional criteria for two-phase flow regimes are based on the theoretical approach of Ref. [12], where geometrical parameters, like vapour volume fraction or interfacial area per unit volume, are correlated with a dimensional quantity, usually the inass flux of the mixture $G_{m}$.

The report by Ishil and Mishima [13] has shown that this approach is inadequate to characterize the regimes in transient flows where the dependence of geometrical parameters on relative phase velocities should not be neglected. Furthermore, it is insufficient to evaluate phase velocities from a given slip ratio; it is mandatory to compute them directly from field equations.

Because implementation of complex-flow-regime maps proposed in Ref. [13] would imply elaborate coding and a multitude of constitutive relations, most advanced computer programmes, like RELAP5/MOD2 [14] or TRAC-PD2 [15], rely on simplified versions of the maps proposed in Ref. [12], 1.e., on maps drawn in the $\left(G_{m}\right.$. a) plane. However, it is generally recognized that the dependence on a dimensional parameter, like $G_{m}$, casts doubt on the reliability of empirical data from which maps have been devised.

By modeling the flow regimes in the BACCHUS code, we have dropped dependence on the dimensional parameter $\mathrm{G}_{\mathrm{m}}$, thereby simplifying the resulting map, which is reduced to three sections of the $(0 \leq \alpha \leq 1)$ interval. Below a lower threshold, we simulated a bubbly flow regime with vapour bubbles dispersed in a continuous liquid phase; above an upper threshold, we assumed an annular-flow regime with a static liquid film of coolant wetting the pins or structural surfaces. In the middle range, a transition between the two flow regimes occurs. In the code, an input value of the void fraction $\alpha_{\min }(\approx 0.5$ to 0.7$)$ is given, below which only the ISM holds. When this threshold is reached in a cell, a smooth transition from the ISM to the SPM is modeled within the range $\alpha_{\mathrm{mIn}} \leq \alpha \leq \alpha_{\min }+0.1$. Above the value $\alpha=$ 
$\alpha_{m i n}+0.1$, only the SPM holds. The main feature involved in the coupling consists in making a weighted average of the coefficients of the two Poisson pressure equations for the separated phases. Otherwise, the link is made as explained in the previous section. An overview of the resulting integrated code version is given in the Appendix.

\section{Mass Transfer Rate Between the Phases}

The mass transfer rate between phases, considered positive for evaporation, is determined by the enthalpy transfer between the phases and by pressure oscillations in the coolant. The smooth variation of pressure in the transition between bubbly and annular flow regimes, obtained as explained in the previous section, is of paramount importance in the calculation of the mass transfer rate, which must likewise vary smoothly with time.

From the analytical viewpoint, it is advantageous to treat the problem in terms of specific entropy of the phases. The analytical treatment proceeds through the following steps.

1. Derivation of the Gibbs equation, which expresses the total time derivative of coolant-specific internal energy in terms of specific entropy.

2. Transformation, by means of the Gibbs equation, of the instantaneous local form of the internal energy equation for a continuum (single-phase) fluid into the local entropy equation.

3. Derivation of the volume-averaged entropy equations for both phases using the phase-indicator function and volume-averaging procedures.

4. Computation of the mass transfer rate using the volume-averaged entropy equations.

This mass exchange model is motivated by that developed by Lyczkowski and Solbrig [16]. 


\subsection{Gibbs Equation}

Formal differentiation with respect to time of the thermodynamic relations expressing the internal specific energy $u$ as function of specific entropy and density $u$ $=u(s, \rho)$ ytelds the Gibbs equation, in its first form, as [17]

$$
\frac{d u}{d t}=T \frac{d s}{d t}-p \frac{d(1 / \rho)}{d t} .
$$

Use of the continuity equation transforms eq. (19) into the second form of the Gibbs equations,

$$
\frac{\mathrm{du}}{\mathrm{dt}}=\mathrm{T} \frac{\mathrm{ds}}{\mathrm{dt}}-\frac{\mathrm{p}}{\mathrm{p}}(\boldsymbol{\nabla} \cdot \mathbf{v})
$$

\subsection{Entropy Equation for a Continuum}

The local internal energy equation for a continuum can be written [18] as

$$
\frac{\partial(\rho u)}{\partial \mathrm{t}}+\nabla \cdot(\rho \mathrm{v} \boldsymbol{\nabla})=-\nabla \cdot \mathbf{q}+\underline{\mathbf{T}}: \nabla \mathbf{v}+\rho \mathbf{r}
$$

In eq. (21), $\mathbf{T}$ is the stress tensor and $r$ is a specific heat source.

Expanding the stress tensor in pressure and shear stress components

$$
\underline{\mathbf{T}}=-\mathrm{p} \mathbf{I}+\underline{\boldsymbol{\tau}}
$$

and using the Gibbs eq. (20), we derive, after some analytical calculation, the entropy equation for a continuum

$$
\frac{\partial(\rho s)}{\partial \mathrm{t}}+\nabla \cdot(\rho s \nabla)=-\frac{1}{T}(\nabla \cdot \mathbf{q})+\frac{1}{\mathrm{l}} \cdot(\mathbf{\tau}: \nabla \nabla)+\frac{\rho}{\mathrm{T}} \mathrm{r} .
$$

\subsection{Volume-Averaged Entropy Equations for the Phases}

The entropy equations of both phases are derived from the local instantaneous entropy equation for a continuum, eq. (23), by means of the volume-averaging procedure, explained in detail in Ref. [19]. It consists of multiplying the local continuum equation by the "phase indicator" $x_{k}(x, t)$ (which has a value of 1 or 0 , 
according to whether the point $x$ lies within phase $k$ or not) and then averaging over the volume. Thus, eq. (23) ylelds

$$
\overline{X_{k} \frac{\partial}{\partial t}(\rho s)}+\overline{X_{k} \nabla \cdot(\rho s \nabla)}=-\overline{\frac{X_{k}}{T}(\nabla \cdot q)}+\overline{\frac{X_{k}}{T}(\underline{\underline{x}}: \nabla \nabla)}+\overline{X_{k} \frac{\rho}{T} r} .
$$

The terms in eq. (24) can be reformulated using the average quantities defined for every phase $(k=\ell, g)$ in Table II. With these definitions and the Identity

$$
\frac{\partial \mathrm{X}_{\mathrm{k}}}{\partial \mathrm{t}}+\nabla_{1} \cdot \nabla \mathrm{X}_{\mathrm{k}}=0
$$

which holds for the phase indicator $X_{k}[19]$. eq. (24) can be rewritten as

$$
\begin{aligned}
\frac{\partial}{\partial t}\left(\overline{\alpha_{k}} \overline{\rho_{k}^{x}} \overline{s_{k}} x, p\right) & +\nabla \cdot\left(\overline{\alpha_{k}} \overline{\rho_{k}^{x}} \overline{s_{k}} x, \rho \overline{\nabla_{k}} x, p\right)=\overline{s_{k j}} \overline{M_{k}}-\nabla \cdot\left(\overline{\alpha_{k}} \overline{\phi_{k}^{x}}\right)+ \\
& +\overline{E_{s k}}+\overline{\alpha_{k}} \overline{D_{s k}}+\overline{\alpha_{k}} \overline{\rho_{k}^{x}} \overline{\sigma_{k}} x, p .
\end{aligned}
$$

Keeping in mind that symbols now denote mean values, in the following, we drop the bars and relative superscripts. The first term on the right-hand side of eq. (26) represents the entropy source due to the mass transfer $M_{k}$ and its associated heat transfer. The last term represents intrinsic heat generation. These terms are modeled as follows:

For the vapour phase $\left(k=g\right.$ and $\left.M_{g}=M\right)$.

Consistent with the assumption that in the SPM, as long as $\alpha<1$, there is no heat transferred directly to the vapour, but the heat transfer occurs only by means of vaporization or condensation of the liquid film, we have

$$
\begin{aligned}
s_{g 1} M & =\frac{h_{g s} M}{T_{s}}=\frac{\phi_{g}}{T_{s}} . \\
\sigma_{s g} & =0 .
\end{aligned}
$$

For the liquid phase $\left(k=\ell, M_{\ell}=-M\right)$.

$$
\begin{aligned}
s_{\ell 1} M_{\ell} & =-\frac{h_{\ell s} M}{T_{s}}=\frac{\phi_{\ell}}{T_{s}}-\frac{Q_{\ell}}{T_{s} V_{f}} . \\
\sigma_{s \ell} & =0 .
\end{aligned}
$$


Equations (27) and (29) define $\phi_{g}$ and $\phi_{l}$, the specific power sources of the vapour and liquid. respectively. It is further assumed that the mass transfer occurs under conditions of thermodynamic equilibrium between the phases. Thus, both phases are assumed to have the same temperature $T_{s}$ and the specific enthalpies $h_{\ell s}$. and $h_{g s}$ are computed along the saturation lines.

Combining eqs. (27) and (29), we obtain

$$
M=\frac{1}{h_{f g}}\left(\phi_{g}+\phi_{l}-\frac{Q_{l}}{V_{f}}\right)=\frac{1}{h_{f g}}\left(\phi-\frac{Q_{l}}{V_{f}}\right) .
$$

with

$$
\phi=\phi_{g}+\phi_{l}
$$

Therefore, the entropy equations for the liquid and vapour phases become

$$
\begin{gathered}
\frac{\partial}{\partial t}\left[(1-\alpha) \rho_{\ell} s_{\ell}\right]+\nabla \cdot\left[(1-\alpha) \rho_{\ell} s_{\ell} \nabla_{\ell}\right]=\frac{\phi_{\ell}}{T_{s}}-\frac{Q_{\ell}}{T_{s} V_{f}}+R_{\ell} . \\
\frac{\partial}{\partial t}\left(\alpha \rho_{g} s_{g}\right)+\nabla \cdot\left(\dot{\alpha} \rho_{g} s_{g} \nabla_{g}\right)=\frac{\phi_{g}}{T_{s}}+R_{g} .
\end{gathered}
$$

with the definitions

$$
\begin{aligned}
& R_{\ell}=-\nabla \cdot(1-\alpha) \phi_{l}^{x}+E_{s l}+(1-\alpha) D_{S \ell} . \\
& R_{g}=-\nabla \cdot \alpha \phi_{g}^{x}+E_{s g}+\alpha D_{s g} .
\end{aligned}
$$

We retain the superscript $x$ to distinguish the entropy fluxes $\phi_{l}^{x}$ and $\phi_{g}^{x}$ from the specific power sources $\phi_{l}$ and $\phi_{g}$.

\subsection{Derivation of Mass Transfer from Entropy Equations}

Summing eqs. (33) and (34), we have a combined entropy equation

$$
\begin{aligned}
& \frac{\partial}{\partial \mathrm{t}}\left[\alpha \rho_{\mathrm{g}} s_{\mathrm{g}}+(1-\alpha) \rho_{\ell} s_{\ell}\right]+. \nabla \cdot\left[\alpha \rho_{\mathrm{g}} s_{\mathrm{g}} \nabla_{\mathrm{g}}+(1-\alpha) \rho_{\ell} s_{\ell} \nabla_{l}\right]= \\
= & \frac{\phi_{\ell}}{\mathrm{T}_{\mathrm{s}}}-\frac{\mathrm{Q}_{\ell}}{\mathrm{T}_{\mathrm{s}} \mathrm{V}_{\mathrm{f}}}+\mathrm{R}_{\mathrm{g}}+\mathrm{R}_{\ell} .
\end{aligned}
$$


Equation (37) is the generalization of eq. (1) of Lyczkowski and Solbrig [16]. Their methodology is used to derive the mass transfer rate.

Expanding the differentials and using the continuity equations, we derive

$$
\begin{aligned}
& M\left(s_{g}-s_{\ell}\right)=\frac{\phi}{T_{s}}-\frac{Q_{\ell}}{T_{s} V_{f}}+R_{g}+R_{l}- \\
& -\left[\alpha \rho_{g}\left(\frac{\partial s_{g}}{\partial t}+\nabla_{g} \cdot \nabla s_{g}\right)+(1-\alpha) \rho_{\ell}\left(\frac{\partial s_{l}}{\partial t}+v_{\ell} \cdot \nabla s_{l}\right)\right] .
\end{aligned}
$$

From the thermodynamic relationships $d q=T \cdot d s=d h-d p / \rho$, we derive for either phase and for the three coordinate directions $x_{1}$

$$
T_{s} \frac{\partial s_{k}}{\partial t}=\frac{\partial h_{k}}{\partial t}-\frac{1}{\rho_{k}} \frac{\partial p}{\partial t} . \quad(k=g, l)
$$

and

$$
\begin{array}{ll}
\mathrm{T}_{\mathrm{s}} \frac{\partial \mathrm{s}_{\mathrm{k}}}{\partial \mathrm{x}_{1}}=\frac{\partial \mathrm{h}_{\mathrm{k}}}{\partial \mathrm{x}_{1}}-\frac{1}{\rho_{\mathrm{k}}} \frac{\partial \mathrm{p}}{\partial \mathrm{x}_{1}} & (\mathrm{k}=\mathrm{g}, \ell) \\
& \left(\mathrm{x}_{\mathrm{i}}=\mathrm{r}, \mathrm{s}, \mathrm{z}\right)
\end{array}
$$

Writing pressure $p$ without subscript $k$, we implicitly make use of the previous hypothesis of equal pressure in both phases within a given computational cell.

From the previous two equations, we obtain

$$
\begin{array}{ll}
\frac{\partial s_{k}}{\partial t}+v_{k} \cdot \nabla s_{k}=\frac{\partial s_{k}}{\partial t}+u_{k i} \frac{\partial s_{k}}{\partial x_{i}}= & \\
=\frac{1}{T_{s}}\left[\frac{\partial h_{k}}{\partial t}-\frac{1}{\rho_{k}} \frac{\partial p}{\partial t}+u_{k i}\left(\frac{\partial h_{k}}{\partial x_{1}}-\frac{1}{\rho_{k}} \frac{\partial p}{\partial x_{1}}\right)\right] & \begin{array}{l}
(k=g, \ell) \\
\left(x_{i}=r, s, z\right)
\end{array}
\end{array}
$$

Introducing eq. (41) into eq. (38), dividing by $\left(s_{g}-s_{\ell}\right)$, and using

$$
T_{s}\left(s_{g}-s_{\ell}\right)=h_{f g} \text {. }
$$

we derive

$$
M=\frac{\phi}{h_{f g}}-\frac{Q_{l}}{h_{f g} V_{f}}+\frac{R_{g}+R_{l}}{s_{g}-s_{l}}-
$$




$$
\begin{gathered}
-\frac{1}{h_{f g}}\left\{\alpha \rho_{g}\left(\frac{\partial h_{g}}{\partial t}+u_{g l} \frac{\partial h_{g}}{\partial x_{l}}\right)+(1-\alpha) \rho_{\ell}\left(\frac{\partial h_{\ell}}{\partial t}+u_{\ell l} \frac{\partial h_{\ell}}{\partial x_{1}}\right)-\frac{\partial p}{\partial t}\right. \\
\left.-\left[\alpha \cdot u_{g l}+(1-\alpha) u_{\ell l}\right]\right\} . \\
(i=r, s, z)
\end{gathered}
$$

Because, on the saturation lines, the liquid- and vapour specific enthalpies are functions of pressure only, we can write

$$
\begin{array}{rlrl}
\frac{\partial h_{k}}{\partial t}=\frac{d h_{k}}{d p} \frac{\partial p}{\partial t} & \\
\frac{\partial h_{k}}{\partial x_{1}}=\frac{d h_{k}}{d p} \frac{\partial p}{\partial x_{1}} . & & (k=g, l) \\
& \left(x_{1}=r, s, z\right)
\end{array}
$$

Hence, we derive, Identically,

$$
\begin{aligned}
& \quad \alpha \rho_{g}\left(\frac{\partial h_{g}}{\partial t}+u_{g 1} \frac{\partial h_{g}}{\partial x_{1}}\right)+(1-\alpha) \rho_{\ell}\left(\frac{\partial h_{\ell}}{\partial t}+u_{\ell 1} \frac{\partial h_{\ell}}{\partial x_{1}}\right)= \\
& =\frac{\partial p}{\partial t}\left[\alpha \rho_{g} \frac{d h_{g}}{d p}+(1-\alpha) \rho_{\ell} \frac{d h_{\ell}}{d p}\right]+ \\
& +\frac{\partial p}{\partial x_{1}}\left[\alpha \rho_{g} u_{g 1} \frac{d h_{g}}{d p}+(1-\alpha) \rho_{\ell} u_{\ell l} \frac{d h_{\ell}}{d p}\right] .
\end{aligned}
$$

Combining eqs. (45) and (43) produces

$$
\begin{aligned}
& M=\frac{1}{h_{f g}}\left(\phi-\frac{Q_{l}}{V_{f}}\right)+\frac{R_{g}+R_{l}}{s_{g}-s_{l}}-\frac{1}{h_{f g}}\left\{\frac{\partial p}{\partial t}\left[\alpha \rho_{g} \frac{d h_{g}}{d p}+(1-\alpha) \rho_{\ell} \frac{d h_{\ell}}{d p}-1\right]\right. \\
& +\frac{\partial p}{\partial x_{1}}\left[\alpha \rho_{g} u_{g l} \frac{d h_{g}}{d p}+(1-\alpha) \cdot \rho_{\ell} u_{\ell^{1}} \frac{d h_{l}}{d p}-\left(\alpha u_{g 1}+(1-\alpha) u_{\ell l}\right)\right] .
\end{aligned}
$$

(c)

Term (a) in eq. (46) gives the mass transfer rate that would be generated if only the heat transfer through the liquid film and to the liquid film were considered. Using the definitions shown in eqs. (35) and (36). we rewrite term (b) in eq. (46) as

$$
\operatorname{Term}(\mathrm{b})=\frac{R_{\mathrm{g}}+\mathrm{R}_{l}}{\mathrm{~s}_{\mathrm{g}}-\mathrm{s}_{l}}=
$$




$$
\frac{1}{s_{g}-s_{l}}\left\{-\nabla \cdot\left[\alpha \overline{\phi_{g}^{x}}+(1-\alpha) \overline{\phi_{l}^{x}}\right]+E_{s g}+E_{s l}+\alpha D_{s g}+(1-\alpha) D_{s l}\right\}
$$

Equation (47) represents the rate of vapour mass generation by heat production due to conductive transfer $\left(\overline{\phi_{k}^{x}}, E_{s k}\right)$ and viscous dissipation $\left(D_{k}\right)$. Term $(b)$ is usually smaller than term (a) but not negligible with respect to term (c). Term (c) represents the contribution of time and space variation of pressure to the rate of vapour mass generation. If the pressure is constant both in time and space, term (c) vanishes. If heat power [term (a)] is suppressed. term (c) becomes dominant because vapour production or condensation is then governed essentially be pressure variations.

The theoretical derivation of vapour mass transfer rate $M$, explained above in the frame of the SPM, is general and can also be applied to the IS! ${ }^{\circ}$ In the limiting case of equal phase velocity (HEM) $\left(H=\left|u_{g}\right| /\left|u_{\ell}\right|=1\right)$, eq. (46) simplifies to

$$
\begin{aligned}
& M_{(\text {HEM })}=\frac{1}{h_{f g}}\left(\phi-\frac{Q_{\ell}}{V_{f}}\right)+\frac{R_{g}+R_{\ell}}{s_{g}-s_{\ell}}- \\
& -\frac{\rho_{m}}{h_{f g}}\left[x \frac{d h_{g}}{d p}+(1-x) \frac{d h_{\ell}}{d p}-\frac{1}{\rho_{m}}\right] \frac{d p}{d t} .
\end{aligned}
$$

Equation (48) extends eq. (23) of Lyczkowski and Solbrig [16].

\section{Code Verification}

The code was extensively verified by numerically simulating several series of electrically heated rod bundle experiments ranging from 7 to 37 pins. The experiments were performed at the Institut für Reaktorentwicklung (IRE) of KRK. Because it is beyond the purpose of the present article to report the numerical verification of the code, we refer the reader to Table III for a summary of the relative work of the past years. The table summarizes the experimental series involved and gives references to both data evaluation and theoretical interpretation of the experiments. 


\section{Conclusions}

The criteria for traditional two-phase now regimes depend on geometrical parameters, like vapour volume fraction or interfacial area per unit volume, correlated with a dimensional quantity, usually the mass flux of the mixture. However, the dependence on a dimensional parameter casts doubt on the reliability of empirical data from which maps have been devised.

By modelling the flow regimes, we have dropped the dependence on dimensional parameters, thereby reducing the resulting map to three sections of the $0 \leq \alpha \leq 1$ interval. Below a lower threshold $(\alpha=0.6)$, we simulated a bubbly flow regime with vapour bubbles dispersed in a continuous liquid phase; above an upper threshold $(\alpha \simeq 0.7)$, we assumed an annular flow regime with a static liquid film of coolant wetting the pins or structural surfaces. In the middle range, a transition between the two flow regimes occurs.

By linking the two-phase models, a smooth transition between the numerical solutions of the respective systems of governing equations must be ensured. Problems related to the link concern

- Computation of mass flows and velocity components of both phases. In the transition between ISM and.SPM, the velocity components must not undergo discontinuity. A smooth transition would not be possible in the usual SM but has been attained in the ISM by proper choice of slip velocities as a function of vold fraction. The smooth transition of the velocity components also assures a continuity in the pressure-drop computation.

- Calculation of pressure drops, taking into account both wall and interfacial friction. In the SPM, the latter is assigned to the vapour phase only.

- Computation of momentum exchange between the phases. We model the momentum exchange due to mass transfer by assigning it to the phase that acquires it, and neglecting the momentum lost by the other phase. 
With these improvements, coupled with validation of the model with experiments, a viable integrated solution procedure has been produced that is superior to using the two separately.

\section{Acknowledgments}

The authors acknowledge the contributions made by Ing. B. Dorr of the German Nuclear Research Center of Karlsruhe in the analysis and computations of two-phase pressure drops and thank Mrs. S. Moll for her excellent work of typing the manuscript.

\section{Nomenclature}

A Surface area $\left(\mathrm{m}^{2}\right)$

$c_{p} \quad$ Specific heat $(\mathrm{J} / \mathrm{kg})$

D Entropy source due to viscous dissipation $\left(\mathrm{W} / \mathrm{m}^{3} \mathrm{~K}\right)$

$D_{h} \quad$ Hydraulic diameter $(m)$

$d_{m} \quad$ Coefficient multiplying pressure increment in the discretized momentum equation $(\mathrm{s} / \mathrm{m})$

E Interfacial entropy source $\left(\mathrm{W} / \mathrm{m}^{3} \mathrm{~K}\right)$

f Friction Coefficient

G Momentum transfer by vaporization or condensation $\left(\mathrm{kg} / \mathrm{m}^{2} \mathrm{~s}^{2}\right)$

g Gravity acceleration $\left(\mathrm{m} / \mathrm{s}^{2}\right)$

H Slip ratio

h Specific enthalpy $(\mathrm{J} / \mathrm{kg})$

I Identity tensor

J Convective plus diffusive flux of momentum $\left(\mathrm{kg} / \mathrm{m} \mathrm{s}^{2}\right)$ 
K Drag function $\left(\mathrm{kg} / \mathrm{m}^{3} \mathrm{~s}\right)$

M Mass transfer rate $\left(\mathrm{kg} / \mathrm{m}^{3} \mathrm{~s}\right)$

p Pressure $\left(\mathrm{N} / \mathrm{m}^{2}\right)$

8 Specific power $\left(\mathrm{W} / \mathrm{m}^{3}\right)$

q Energy flux $\left(W / m^{2}\right)$

R Friction pressure losses $\left(\mathrm{kg} / \mathrm{m}^{2} \mathrm{~s}^{2}\right)$

Re Reynolds number

$r$ Radial coordinate (m)

$S_{\phi} \quad$ Generalized source (dimensions given for momentum equation) $\left(\mathrm{kg} / \mathrm{m}^{2} \mathrm{~s}^{2}\right.$ )

s Azimuthal coordinate (m); specific entropy $(\mathrm{J} / \mathrm{kg} \mathrm{K})$

T Temperature (K)

T Stress tensor $\left(\mathrm{v} / \mathrm{m}^{2}\right)$

t Time (s)

US Slip velocity normalized to the mixture velocity

u Component of coolant velocity $(\mathrm{m} / \mathrm{s})$; internal specific energy $(\mathrm{J} / \mathrm{kg})$

$\hat{\mathrm{u}} \quad$ Mass flux resulting from discretization of momentum equation $\left(\mathrm{kg} / \mathrm{m}^{2} \mathrm{~s}\right)$

$\nabla, \mathbf{V}$ Velocity vector $(\mathrm{m} / \mathrm{s})$

w Component of coolant veloctty $(\mathrm{m} / \mathrm{s})$

X Phase indicator function

x Thermodynamic quality; coordinate direction $(\mathrm{m})$ 
z Axial coordinate (m)

\section{Greek}

$\alpha \quad$ Volume fraction

$\Gamma \quad$ Diffusion coefficient (dimensions given for momentum equation) $(\mathrm{kg} / \mathrm{m} \mathrm{s})$

$\gamma \quad$ Surface permeability

$\delta \quad$ Liquid film thickness (m)

$\eta \quad$ Weighting factor

$\lambda \quad$ Thermal conductivity $(\mathrm{W} / \mathrm{m} \cdot \mathrm{K})$

$\mu \quad$ Dynamic viscosity $(\mathrm{kg} / \mathrm{m} \cdot \mathrm{s})$

$\rho \quad$ Microscopic density $\left(\mathrm{kg} / \mathrm{m}^{3}\right)$

$\rho^{\prime} \quad$ Macroscopic density $\left(\mathrm{kg} / \mathrm{m}^{3}\right) ; \rho_{g}^{\prime}=\alpha \rho_{g} ; \rho_{\ell}^{\prime}=(1-\alpha) \rho_{\ell}$

$\sigma \quad$ Entropy source due to intrinsic heat generation $(\mathrm{W} / \mathrm{kgK})$

I $\quad$ Shear stress $\left(\mathrm{kg} / \mathrm{m} \cdot \mathrm{s}^{2}\right)$

Q Transported scalar; specific power source $\left(\mathrm{W} / \mathrm{m}^{3}\right)$

$\phi$ Entropy flux $\left(\mathrm{W} / \mathrm{m}^{2} \mathrm{~K}\right)$

$\phi^{2}$ Two-phase pressure-drop multiplier

$\Psi \quad$ Friction coefficient

Operators

$\nabla \cdot \quad$ Divergence

$\nabla \quad$ Gradient 
$\frac{d}{d t}=\frac{\partial}{\partial t}+\nabla \cdot \nabla$ Total derivative

[a,b] Denotes the maximum of the two real numbers $a, b$

\section{Indices}

f Fluid

g Vapour

1 Dummy index/interface

ISM Improved Slip Model

k Phase indicator

$\ell \quad$ Liquid

m Mixture

n Superscript for time discretization

s Saturation/entropy

S1 Slip

SPM Separated Phases Model

References

1. M. Bottoni, B. Dorr, C. Homann, and D. Struwe, BACCHUS-3D/SP; A computer programme for the three-dimensional description of sodium single-phase flow in bundle geometry, Report KfK 3376 (July 1983).

2. M. Bottoni, B. Dorr, C. Homann, and D. Struwe, BACCHUS 3D/SP, a computer programme to describe transient three-dimensional single phase flow in LMFBR rod bundles, Nucl. Technol. 71 (1985) 43-67. 
3. J. N. Lillington, SABRE-3: A computer programme for the calculation of steady-state bolling in rod cluster, UKAEA Report AEEW-M-1647 (i979).

4. M. Aral and N. Hirata, Analysis of the central blockage wake in a LMFBRsubassembly, Nucl. Engrg. Des. 45 (1978) 127-132.

5. H. Ninokata and T. Okano, SABENA: Subassembly boilling evolution numerical analysis, Nucl. Engrg. Des. 120 (1990) 349-367.

6. M. Bottoni, B. Dorr, C. Homann, and D. Struwe, State of development of the computer programme BACCHUS-3D/TP for the description of transient twophase flow conditions in LMFBR fuel pin bundles, Nucl. Engrg. Des. 100 (1987). 321-349.

7. M. Bottoni, B. Dorr, and C. Homann, The three-dimensional transient twophase flow computer programme BACCHUS-3D/TP. Report KfK 4760, 1992, to appear.

8. L. Fox, An Introduction to Numerical Linear Algebra (Clarendon Press, Oxford, 1964).

9. M. Bottoni, A variant of the ADI-method for two-phase flow calculations, submitted to Computer and Fluids, to appear.

10. M. S. Plesset, N. Zuber, and I. Catton, eds, Transient Two-Phase Flow (Heinisphere Publishing Corporation, Washington, 1983).

11. R. W. Lyczkowski, D. Gidaspow, and C. W. Solbrig, Multiphase flow-models for nuclear, fossil, and tiomass energy production, in: Advances in Transport Processes, Vol. 2, A. S. Majumdar and R. A. Mashelkar, eds. (Wiley Eastern Ltd, New Delhi, 1982) 198-340.

12. Y. Taitel, D. Bornea, and A. E. Dukler, Modelling flow pattern transitions for steady state upward gas-liquid flow in vertical tubes, AIChE J. 26 (1980).

13. M. Ishil and K. Mishima, Study of two-fluid model and interfacial area, Argonne National Laboratory Report, ANL-80-111, NUREG/CR-1873 (1980). 
14. V. H. Ransom et al., RELAP5/MOD2 code manual, Vol. I, code structure, system models and solution methods. EGG-SAAM-6377 (1984).

15. TRAC-PD2 - An advanced-best estimate computer program for pressurized water reactor loss of coolant accident analysis, Los Alamos National Laboratory Report LA-8709-MS, NUREG/CR-2054 (1981).

16. R. W. Lyczkowski and C. W. Solbrig, Constitutive rate equations for flowing phases flashing at unequal velocities and temperatures, Proc. of Topical Meeting on Thermal Reactor Safety, July 31-August 5, 1977, Sun Valley, Idaho. CONF-77078, Vol. 2, pp. 2-425 to 2-442, American Nuclear Society, Hinsdale, Illinois (1977).

17. H. B. Callen. Themodynamics (John Wiley and Sons, New York, 1960).

18. R. B. Bird, W. E. Stewart, and E. N. Lightfoot, Transport Phenomena (John Wiley and Sons, New York, 1980).

19. M. Bottoni and W. Sengpiel, On modelling. mathematical analysis and numerical treatment of three-dimensional transient two-phase coolant flow in engineering systems, Proc. 3rd Brazilian Thermal Science Meeting, ENCIT 90, December 10-12, 1990, Itapema, S.C., Brazil.

20. J. Aberle, A. J. Brook, W. Peppler, H. Rohrbacher, and K. Schleisiek, Sodium boiling experiments in a 7-Pin bundle under flow rundown conditions, Report KfK 2378 (1976).

21. A. Kaiser, Natrium-Siedeexperimente zum LOF-Störfall in einem elektrisch beheizten Siebenstab-Bündel mit SNR Mk II-Geometrie, Report KfK 3058 (December 1980).

22. F. Huber, K. Mattes, W. Peppler, and W. Till, Loss of flow experiments in sodium with an electrically heated 37-pin bundle with sinusoidal axial heat flux distribution, Proc. of ANS/ENS Intl. Topical Meeting on LMFBR Safety and Related Design and Operational Aspects, July 19-22, 1982, Lyon, France. 
23. F. W. Peppler, Sodium boiling experiments in bundle geometries under fast transient and steady state conditions. Proc. Thermohydraulics of Liquid Metals, May 30-June 3, 1983, Rhode-Saint-Genèse. Belgium.

24. B. Bottoni, B. Dorr, C. Homann, F. Huber, K. Mattes, W. Peppler, and D. Struwe, Experimental and numerical investigations of sodium boiling experiments in pin bundle geometry, Nucl. Technol. 89 (1990) 56-82.

25. M. Bottoni, B. Dorr, and C. Homann, Flow regime dependent modelling of twophase flow in 3D-subassembly geometry and its experimental validation, Proc. ANS/ENS Intl. Fast Reactor Safety Meeting, August 12-16, 1990, Snowbird, Utah.

26. F. Huber, A. Kaiser, K. Mattes, and W. Peppler, Steady state and transient sodium boiling experiments in a 37-pin bundle, Nucl. Eng. Des. 100 (1987) 377-386.

27. A. Kaiser, F. Huber, M. Bottoni, and B. Dorr, Contributions to sodium boiling heat transfer, pressure drop, and void distribution in multi-pin geometry, Proc. of Fourth Intl. Topical Meeting on Nuclear Reactor Thermal-Hydraulics, NURETH-4, October 10-13, 1989, Karlsruhe, Vol. 1, pp. 610-616. 


\section{APPENDIX \\ Sequence of Main Calculations Performed to Allow \\ a Smooth Transition from ISM to SPM}

1) Solve the Poisson equation for pressure

For $\alpha \leq \alpha_{\min }$.

$$
A_{m o}^{n+1} p_{o}^{n+1}-\sum_{1}^{6} \beta A_{m \beta}^{n+1} p_{\beta}^{n+1}=R_{m o}^{n+1}
$$

For $\alpha_{\min }<\alpha \leq \alpha_{\min }+0.1$,

$$
\begin{aligned}
& {\left[\eta A_{m o}^{n+1}+(1-\eta)\left(A_{l o}^{n+1}+A_{g o}^{n+1}\right)\right] p_{o}^{n+1}-} \\
& -\sum_{1}^{6}\left[\eta A_{m \beta}^{n+1}+(1-\eta)\left(A_{\ell \beta}^{n+1}+A_{g \beta}^{n+1}\right) p_{\beta}^{n+1}\right]=\eta R_{m o}^{n+1}+(1-\eta)\left(R_{l o}^{n+1}+R_{g o}^{n+1}\right) \\
& \eta=1-\left(\alpha-\alpha_{m l n}\right) / 0.1
\end{aligned}
$$

For $\alpha>\alpha_{\min }+0.1$.

$$
\left(A_{\ell 0}^{n+1}+A_{g o}^{n+1}\right) p_{o}^{n+1}-\sum_{\beta}^{6}\left(A_{\ell \beta}^{n+1}+A_{g \beta}^{n+1}\right) p_{\beta}^{n+1}=R_{\ell 0}^{n+1}+R_{g o}^{n+1} \text {. }
$$

ii) Update physical properties of both phases according to the new pressure distribution

iii) Compute mass flow components for both phases of mixture

For $\alpha \leqq \alpha_{\min }$,

$$
\left(\rho_{m} u_{m}\right)_{1+1 / 2}^{n+1}=\hat{u}_{m, 1+1 / 2}-d_{m, 1+1 / 2} \Delta p_{i}^{n+1} \quad(i=r, s, z)
$$

Hence compute mass flow components of liquid and vapour phases

$$
\begin{aligned}
& \left(\rho_{\ell}^{\prime} u_{\ell}\right)_{1+1 / 2}^{\mathrm{n}+1}=\left(\rho_{\ell}^{\prime} u_{\mathrm{m}}\right)_{1+1 / 2}\left[1-x U_{\mathrm{S} \ell}^{\mathrm{N}}(\alpha)\right]_{1+1 / 2}, \\
& \left(\rho_{\mathrm{g}}^{\prime} u_{\mathrm{g}}\right)_{1+1 / 2}^{\mathrm{n}+1}=\rho_{\mathrm{g} \cdot 1+1 / 2}^{\prime}\left[\mathrm{u}_{\ell}+\mathrm{U}_{\mathrm{S} \ell}^{\mathrm{N}} \mathrm{u}_{\mathrm{m}}\right]_{1+1 / 2} \quad(i=\mathrm{r}, \mathrm{s}, \mathrm{z}) .
\end{aligned}
$$


For $\alpha_{\min }<\alpha \leq \alpha_{\min }+0.1$.

Let us denote with superscripts 1 and 2 values calculated with the ISM and SMP. respectively. Then take the weighted values.

$$
\begin{aligned}
& \left(\rho_{m} u_{m}\right)_{1+1 / 2}=\eta\left(\rho_{m} u_{m}\right)_{1+1 / 2}^{1}+(1-\eta)\left(\rho_{m} u_{m}\right)_{1+1 / 2}^{2} \\
& \left(\rho_{\ell}^{\prime} u_{\ell}\right)_{1+1 / 2}=\eta\left(\rho_{\ell}^{\prime} u_{\ell}\right)_{1+1 / 2}^{1}+(1-\eta)\left(\rho_{\ell}^{\prime} u_{\ell}\right)_{1+1 / 2^{\prime}}^{2} \\
& \left(\rho_{g}^{\prime} u_{g}\right)_{1+1 / 2}=\eta\left(\rho_{g}^{\prime} u_{g}\right)_{1+1 / 2}^{1}+(1-\eta)\left(\rho_{g}^{\prime} u_{g}\right)_{1+1 / 2}^{2} \quad(i=r, s, z)
\end{aligned}
$$

For $\alpha_{\min }+0.1<\alpha$,

$$
\left(\rho_{\ell}^{\prime} u_{\ell}\right)_{1+1 / 2}^{n+1}=\hat{u}_{\ell, 1+1 / 2}-d_{\ell, 1+1 / 2} \Delta p_{1}
$$

$\left(\rho_{g}^{\prime} u_{g}\right)_{1+1 / 2}^{n+1}=\hat{u}_{g, 1+1 / 2}-d_{g, 1+1 / 2} \Delta p_{1} \quad(i=r, s, z)$

Hence, compute mass flow components of the mixture

$$
\left(\rho_{m} u_{m}\right)_{1+1 / 2}^{n+1}=\alpha \cdot\left(\rho_{g} u_{g}\right)_{1+1 / 2}^{n+1}+(1-\alpha)\left(\rho_{\ell} u_{\ell}\right)_{1+1 / 2}^{n+1} \quad(i=r, s, z)
$$

\section{iv) Compute two-phase prissure drops}

For $\alpha \leq \alpha_{\min }$.

$$
\begin{array}{ll}
\frac{\Delta p}{\Delta x_{1}}=\left(\frac{d p}{d x_{1}}\right)_{m} \phi_{I S M}^{2}+\frac{f\left(R e_{m}\right)}{2 D_{h}}\left(\rho_{m} u_{m i}\right)^{n+1}\left|u_{m i}\right| \phi_{I S M}^{2}, & \\
\phi_{I S M}^{2}=1+K_{1}=1+c\left|u_{g l}-u_{\ell 1}\right|=1+c\left|u_{m i}\right| U_{S \ell l}^{N}(\alpha) & (i=r, s, z) \\
(c \simeq 1-1.5)
\end{array}
$$

For $\alpha_{\min }<\alpha \leqq \alpha_{\min }$.

$$
\phi_{\text {ISM }}^{2}=\frac{\left(\frac{d p}{d z}\right)_{l}+\left(\frac{d p}{d z}\right)_{g} \phi_{S P M}^{2}}{\left(\frac{d p}{d z}\right)_{m}}
$$

$$
\phi_{\mathrm{SPM}}^{2}=1+300 \delta / \mathrm{D}_{\mathrm{h}} .
$$


For $\alpha_{m ! n}+0.1<\alpha_{\text {. }}$

$$
\begin{aligned}
\left(\frac{d p}{d z}\right)_{2 \phi} & =\left(\frac{d p}{d z}\right)_{l}+\left(\frac{d p}{d z}\right)_{l}=R_{\ell z}+R_{g z}, \\
\left(\frac{d p}{d z}\right)_{l} & =R_{\ell z}=\frac{f\left(R e_{\ell}\right)^{n+1}}{2 D_{h}}\left(\rho_{\ell} w_{\ell}\right)^{n+1}\left|w_{\ell}\right|^{n+1}, \\
\left(\frac{d p}{d z}\right)_{1} & =R_{g z}=-K\left(w_{\ell}-w_{g}\right)=\frac{2 \psi_{1} \rho_{g} w_{g}^{2}}{D_{h}} \\
& =\left\{\frac{2 \psi_{i} \rho_{g} w_{g}^{2}}{D_{h}}\left(1+300 \delta / D_{h}\right)\right\} \\
& =\frac{f\left(R_{g}\right)^{n+1}\left(\rho_{g} w_{g}\right)^{n+1}\left|w_{g}\right|^{n+1}}{D_{h}} \phi_{S P M}^{2}=\left(\frac{d p}{d z}\right)_{g} \phi_{S P M}^{2} .
\end{aligned}
$$

with

$$
\begin{aligned}
& \left(\frac{d p}{d z}\right)_{g}=\frac{f\left(R e_{g}\right)}{2 D_{h}}\left(\rho_{g} w_{g}\right)^{n+1}\left|w_{g}\right|^{n+1}, \\
& \phi_{S P M}^{2}=\left(1+300 \delta / D_{h}\right)^{n} .
\end{aligned}
$$

v) Solve Poisson equation for enthalpy

$$
{ }^{H} A_{o}^{n+1} h_{o m}^{n+1}-\sum_{1}^{6} \beta{ }^{H} A_{\beta}^{n+1} h_{\beta m}^{n+1}={ }^{H} R_{o}^{n+1}
$$

vi) Undate physical properties of liquid vapour and mixture according to new enthalpy distribution

vii) Compute updated void fraction (from the continuity equation)

$$
\alpha^{n+1}=\frac{1}{\rho_{\ell}^{n+1}-\rho_{g}^{n+1}}\left[\rho_{\ell}^{n+1}-\rho_{m}^{n}+\frac{\Delta t}{\varepsilon} \sum_{1}^{6} \frac{1}{\Delta x_{1}} \Delta\left(\gamma_{1} \rho_{m} u_{m l}\right)^{n+1}\right](1=r, s, z) \text { (A.19) }
$$

vii) Compute updated thermodynamic quality 


$$
x^{n+1}=\frac{h_{m}^{n+1}-h_{\ell}^{n+1}}{h_{g}^{n+1}-h_{\ell}^{n+1}}
$$


Table I. Terms for Equations in the General Form of Eq. (1). $R_{i}$ represents friction pressure losses, $K$ is a drag function representing momentum exchange between the phases, and $[a, b]$ represents the maximum of the two real numbers a and $b$.

\begin{tabular}{|c|c|c|c|c|c|c|}
\hline Equation & $\rho$ & $\phi$ & $u_{i}$ & $\Gamma_{\phi}$ & $\mathrm{S}_{\phi}$ & $\begin{array}{c}\text { Equation } \\
\text { Number }\end{array}$ \\
\hline $\begin{array}{l}\text { Improved Slip Model (ISM) } \\
\text { mixture continuity }\end{array}$ & $\rho_{\mathrm{m}}$ & 1 & $\mathrm{u}_{\mathrm{m} 1}$ & 0 & 0 & $\mathrm{~T}-1.1$ \\
\hline mixture momentum & $\rho_{\mathrm{m}}$ & $\mathbf{u}_{\mathrm{mj}}$ & $\mathrm{u}_{\mathrm{mi}}$ & $\mu_{\mathrm{m}}$ & $\begin{array}{l}\rho_{m} g_{i}-R_{i}-\partial p / \partial x_{i} \\
-\partial\left[x(1-x) \rho_{m} V_{S \ell_{i}} V_{S \ell, j}\right] / \partial x_{j}\end{array}$ & $\mathrm{~T}-\mathrm{I} .2$ \\
\hline mixture energy & $\rho_{\mathrm{m}}$ & $\mathrm{hm}$ & $\mathrm{u}_{\mathrm{mI}}$ & $\lambda_{\mathrm{m}} / \mathrm{c}_{\mathrm{pm}}$ & 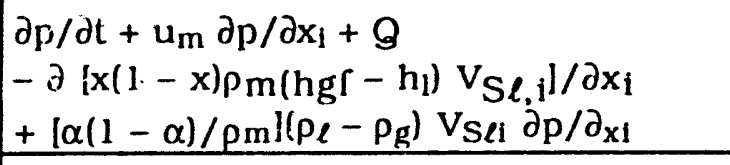 & $T-1.3$ \\
\hline $\begin{array}{l}\text { Separated Phases Model (SPM) } \\
\text { vapour continuity }\end{array}$ & $\rho_{\mathrm{g}}^{\prime}$ & 1 & $u_{\mathrm{gi}}$ & 0 & 0 & $T-1.4$ \\
\hline liquid contin sity & $\rho_{\ell}^{\prime}$ & 1 & $\mathrm{u}_{\ell \mathrm{i}}$ & 0 & 0 & $T-1.5$ \\
\hline vapour momentum & $\rho_{g}^{\prime}$ & $u_{g j}$ & $u_{g i}$ & $\mu_{\mathrm{g}}$ & $\begin{array}{l}\rho_{g}^{\prime} g_{1}-R_{g 1}-\alpha \partial p / \partial x_{1}+K\left(u_{\ell 1}-u_{g 1}\right) \\
+[0, M] u_{\ell 1}-[0,-M] u_{g 1} \\
\end{array}$ & $\mathrm{~T}-\mathrm{I} .6$ \\
\hline liquid momentum & $\rho_{\ell}^{\prime}$ & $u_{\ell j}$ & $u_{\ell i}$ & $\mu_{\ell}$ & $\begin{array}{l}\rho_{\ell}^{\prime} g_{1}-R_{\ell 1}-(1-\alpha) \partial p / \partial x_{1}-K\left(u_{\ell i}-u_{g i}\right) \\
-[0, M] u_{\ell 1}-[0,-M] u_{g i}\end{array}$ & $\mathrm{~T}-1.7$ \\
\hline mixture energy & $\rho_{\mathrm{m}}$ & $\mathrm{hm}$ & $\mathrm{u}_{\mathrm{ml}}$ & $\lambda_{\mathrm{m}} / \mathrm{c}_{\mathrm{pm}}$ & $\begin{array}{l}\partial \mathrm{p} / \partial \mathrm{t}+\mathrm{u}_{\mathrm{m}} \partial \mathrm{p} / \partial \mathrm{x}_{1}+Q \\
-\partial\left[\mathrm{x}(1-\mathrm{x}) \rho_{\mathrm{m}}\left(\mathrm{hgf}_{\mathrm{g}}-\mathrm{h}_{\mathrm{l}}\right) \mathrm{v}_{\mathrm{S} \ell, \mathrm{i}}\right] / \partial \mathrm{x}_{\mathrm{i}} \\
+\left[\alpha(1-\alpha) / \rho_{\mathrm{m}}\right]\left(\rho_{\ell}-\rho_{\mathrm{g}}\right) \mathrm{v}_{\mathrm{S} \ell \mathrm{i}} \partial \mathrm{p} / \partial_{\mathrm{xi}}\end{array}$ & $T-1.8$ \\
\hline
\end{tabular}




\section{Table II. Definition of Volume-Averaged guantities for the Phases ( $k=\ell, g)\left(\nabla_{1}=\right.$ interface velocity)}

Phase volume fraction

$$
\overline{\alpha_{k}}=\overline{X_{k}}
$$

Density

$$
\overline{\rho_{k}^{x}}=\frac{\overline{X_{k} \rho}}{\overline{\alpha_{k}}} \quad\left(\mathrm{~kg} / \mathrm{m}^{3}\right)
$$

Velocity

$$
\overline{\nabla_{k}^{x, \rho}}=\frac{\overline{X_{k} \rho \nabla}}{\overline{\alpha_{k}} \overline{\rho_{k}}}
$$

$(\mathrm{m} / \mathrm{s})$

Entropy

$$
\overline{s_{k}^{x, \rho}}=\frac{\overline{X_{k} \rho s}}{\overline{\alpha_{k}} \rho_{k}^{x}}
$$

Entropy flux

$$
\overline{\phi_{k}^{x}}=\frac{\overline{x_{k} \frac{q}{T}}}{\overline{\alpha_{k}}}
$$

Mass transfer rate

$$
\overline{M_{k}}=\overline{\rho\left(\nabla-\nabla_{i}\right) \cdot \nabla X_{k}}
$$

Interfacial entropy transfer

$$
\overline{s_{k d}} \overline{M_{k}}=\overline{\rho s\left(\nabla-\nabla_{l}\right) \cdot \nabla X_{k}} \quad\left(W / m^{3} K\right)
$$

Interfacial entropy source

$$
\overline{E_{s k}}=\overline{q \cdot \nabla \frac{X_{k}}{T}}
$$

$\left(\mathrm{W} / \mathrm{m}^{3} \mathrm{~K}\right)$

Entropy source due to viscous dissipation

$$
\overline{D_{s k}}=\frac{\overline{X_{k}}(\underline{\tau}: \nabla v)}{\overline{\alpha_{k}}}
$$

Entropy source due to intrinsic heat generation

$$
\overline{\sigma_{s k}^{x_{j} \rho}}=\frac{\overline{X_{k} \rho r}}{\overline{\alpha_{k}} \overline{p_{k}^{x} T}}
$$

(W/kg K) 
Table III. Summary of Experimental Seriess Providing Data for the Valldation of the BACCHUS-3D/TP Program

\begin{tabular}{|c|c|c|c|}
\hline \multirow{2}{*}{$\begin{array}{c}\text { Experimental } \\
\text { Series }\end{array}$} & \multicolumn{1}{c|}{$\begin{array}{c}\text { Experiment } \\
\text { Characteristics }\end{array}$} & $\begin{array}{c}\text { References for } \\
\text { Experimental } \\
\text { Data }\end{array}$ & Simulations \\
\hline $\begin{array}{l}\text { 1. NSK (7-2) 7-Pin } \\
\text { Bundle Expts., Runs } \\
\text { 16. 24, 28 }\end{array}$ & $\begin{array}{l}\text { Loss-of-flow sodium } \\
\text { bolling expts. Slow (runs } \\
16,24) \text { and fast (run 28) } \\
\text { transients }\end{array}$ & 20 & 2,6 \\
\hline $\begin{array}{l}\text { 2. NSK (7-3) 7-Pin } \\
\text { Bundle Expts., Run 21 }\end{array}$ & $\begin{array}{l}\text { Loss-of-flow sodium } \\
\text { boilling expts. with one } \\
\text { unheated pin }\end{array}$ & 21 & 2 \\
\hline $\begin{array}{l}\text { 3. KNS 37-Pin Bundle } \\
\text { Expts., Runs S11, L03 } \\
\text { (single phase). Runs } \\
\text { L22, L60, L58 (two } \\
\text { phase) }\end{array}$ & $\begin{array}{l}\text { Loss-of-flow sodium } \\
\text { boiling expts. with } \\
\text { cosinus-shaped axial } \\
\text { power profile }\end{array}$ & 22,23 & $2,6,24,25$ \\
\hline $\begin{array}{l}\text { 14. KNS 37-Pin Bundle } \\
\text { Expts.. Run S33 }\end{array}$ & $\begin{array}{l}\text { Steady-state boiling } \\
\text { experiments }\end{array}$ & 26,27 & 27 \\
\hline
\end{tabular}


Caption for Fig. 1

Control volumes and indexing conventions shown for one-half of a 37-pin bundle 


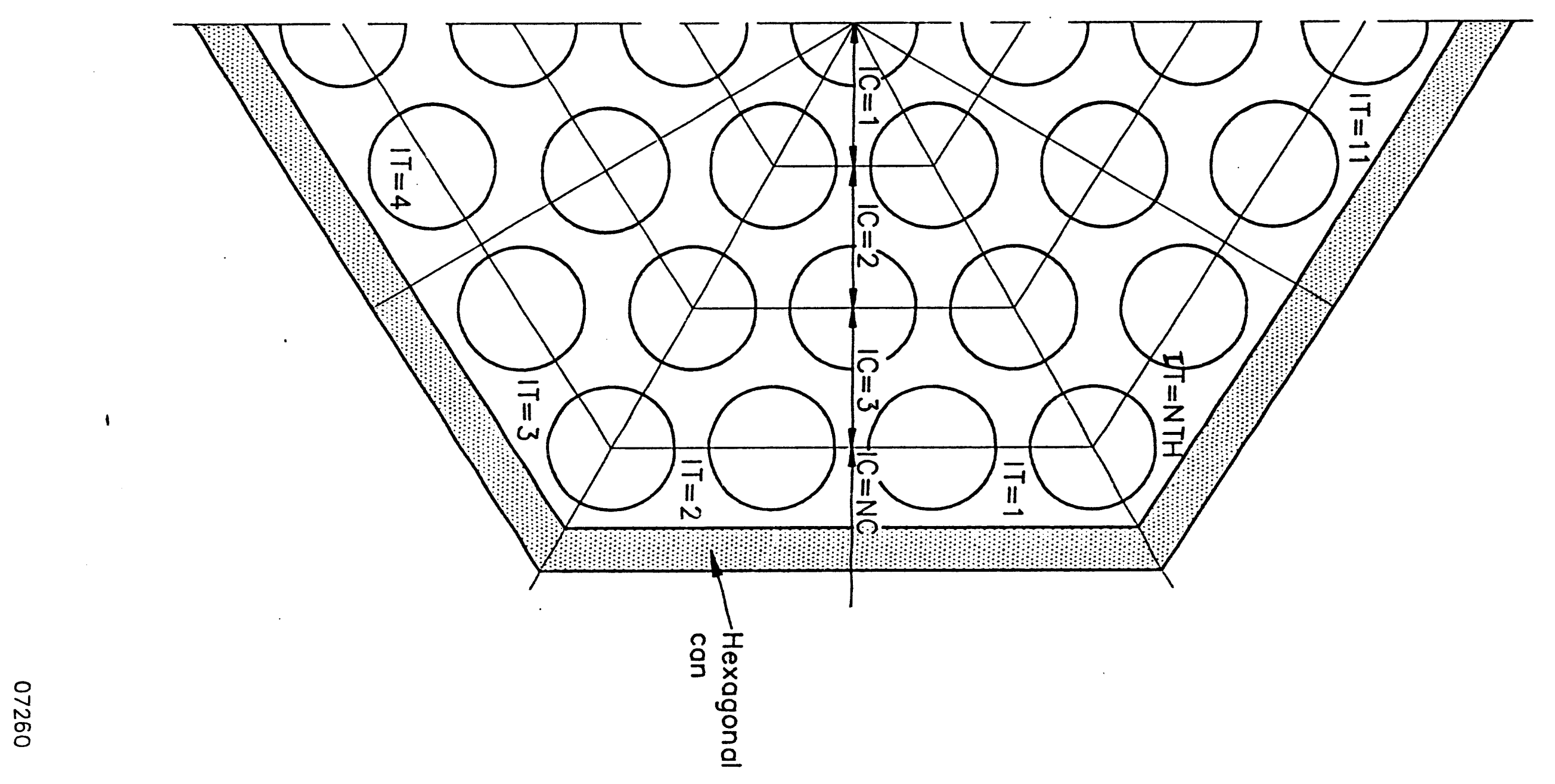



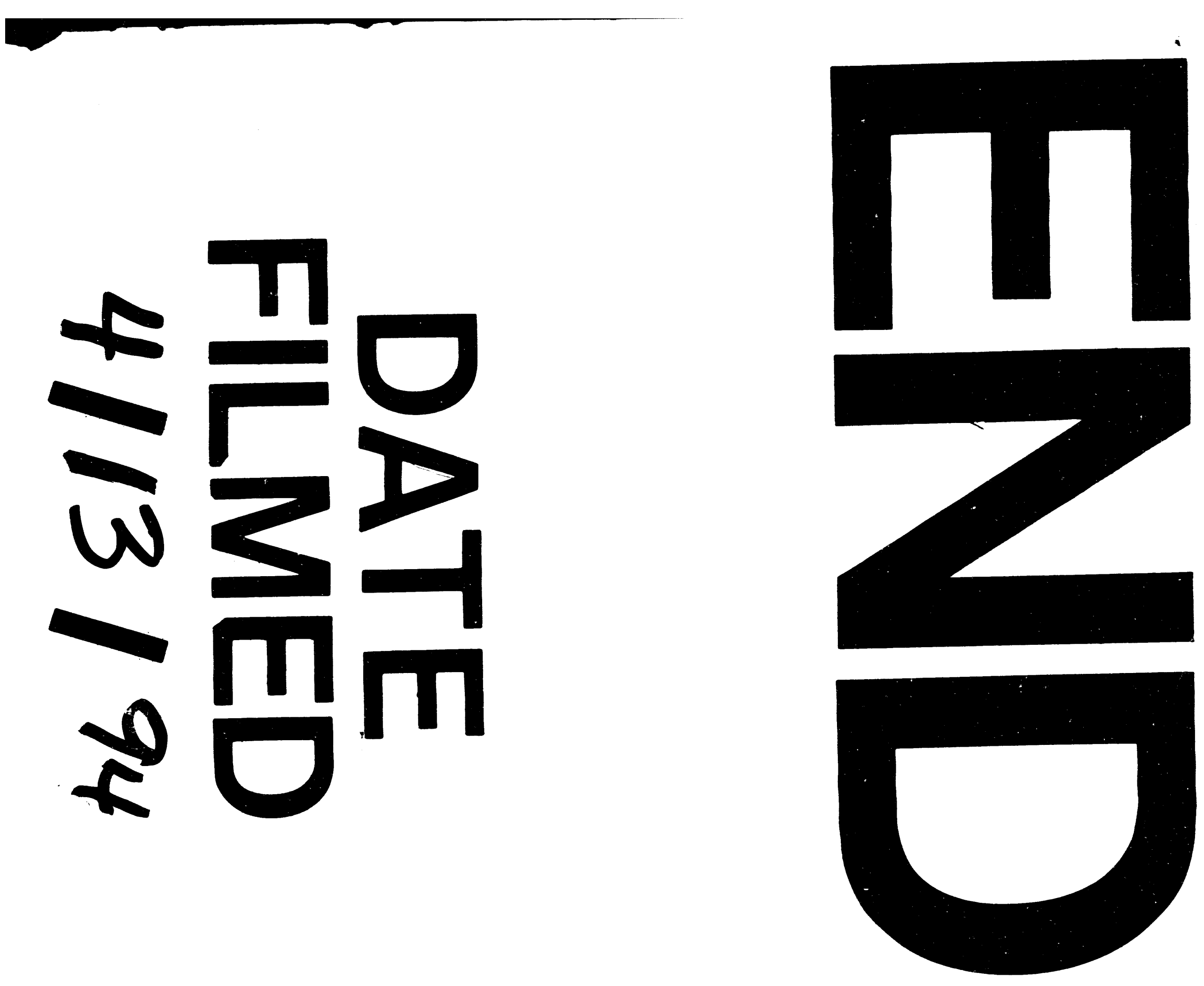
